\title{
E-Business Education: A Comparison of Graduate Programs and Curricula
}

\author{
James E. Novitzki \\ Johns Hopkins University, Baltimore, MD, USA \\ inovitzki@iphu.edu
}

Abstract

This study looks at both MBA and MS E-business programs. Specifically it looks at the number and types of courses offered in these programs and compares and contrasts what is offered between the MS and MBA programs, and also between the different groups of schools being studied. Results indicate that there is no real consensus in what knowledge is core to the concentration. The programs offered at any particular school seem to have only incidental agreement with other programs, and many seem to be the result of faculty skills available and requests for specific skills from organizations, rather than a logical integrated approach to the issues inherent in the global issues of E-business. There appears to be a major need to determine the core knowledge that is critical in the design, development, management, and operation of E-business in organizations to produce graduates with consistent knowledge that is school independent.

Keywords: Electronic Commerce, Electronic Business, MBA, MS, curriculum, required courses.

\section{Introduction}

This paper discusses some of the issues and concerns voiced by those tasked with planning and developing Electronic Business or Electronic Commerce programs at their schools and practitioners and students trying to find a "good" E-business program. The main issue seems to resolve around the questions of whether Electronic Commerce/Business is merely a concentration or is a mindset that should be presented as a key element across the entire curriculum. If it is a concentration, then what should and should not be included? This is not a new discussion, but it is one that has still not been satisfactorily resolved. This paper looks at three groups of graduate business schools and compares and contrasts their programs to see what consistencies and inconsistencies exist in the implementation of Electronic Business/Commerce programs whether they are MBA concentrations or MS concentrations.

\section{Background}

For the purposes of this paper, academic programs with the names Electronic Business, Electronic Com merce, E-Business, E-Commerce, Internet Commerce, et cetera will be referred to generically as Ebusiness. The current economic downturn has not blunted the issues and concerns related to E-business. Organizations are still focused on the potential of E-business to increase their competitiveness and im-

Material published as part of these proceedings, either on-line or in print, is copyrighted by Informing Science. Permission to make digital or paper copy of part or all of these works for personal or classroom use is granted without fee provided that the copies are not made or distributed for profit or commercial advantage AND that copies 1) bear this notice in full and 2) give the full citation on the first page. It is permissible to abstract these works so long as credit is given. To copy in all other cases or to republish or to post on a server or to redistribute to lists requires specific permission from the publisher at Publister@intommingscience.org prove profitability (Payne, 2001). Glenn

McLoughlin (2000) reports that although the rate of E-business growth has slowed it still leads other sectors particularly in countries outside of the U.S. The picture is not entirely good, however. Booker (1998) and Lederer, et al (2001) point out that while many organizations are still searching for the ideal E-business model, others have backed away 
from E-business given the serious problems they have encountered in trying to develop their systems. Many companies, as evidenced by the dot COM retrenchment, have not been successful in improving their organizations' competitiveness or profitability through the use of various E-business principles and models.

Barlas (2001) and Deakin (2001) suggest that the proliferation of E-business programs indicates the importance of the topic as an academic field of study and also that the field is coming of age. A study done by Mitchell and Strauss (2001) supports this contention and identifies several skill and cognitive based clusters that they felt were common to many programs. King et al (2001) and Etheridge al (2001) present findings which show that while there may be some broad clusters of knowledge, there is still considerable variety in course offerings between schools and considerable change in offerings from year to year in this rapidly evolving field. King et al (2001) also reports that programs are often driven more by faculty skill and stakeholder wants rather than academic focus or need.

There have been several articles (Herrmann and Pernul (1999), Teo and Too (2000), and Williams et al (2000)) which indicate that while there is significant difficulty in identifying the key issues in dealing with E-business, there is an even greater problem developing the programs that can best communicate this information to students and practitioners in the field. Patricia Sendell (1999) presented a survey of EBusiness offerings and identified a large number of courses which were included as E-business offerings at the schools surveyed. The problem of a rapidly evolving environment and a developing curriculum has forced many schools to create new methodologies to order to address the dilemma about how to adapt their programs in a manner that is both academically sound and which still meets the needs of students to be able to perform effectively as practitioners in this field. Ferorowicz and Gogan (2001) describe one of the tools that has allowed some schools to rapidly develop curricula, Fast-Cycle Development Strategies. This tool can, by its ability to choose different methodologies, cause some other problems. If the stakeholder-driven methodology is used exclusively, it can result in piecemeal offerings that are stovepipe in nature, do not interact with other courses, and can result in programs that are school, vender, and industry specific.

\section{Current Study}

There is, as was described above, a wide and varied perspective about E-business, its meaning, impact, and efficacy. There are also a variety of views regarding how E-business should be presented in an academic environment. The problem is complicated because a varied mix of institutions and schools offers these programs for a wide variety of audiences (King et al, 2001). A search of the World Wide Web shows E-business programs appearing in business schools, engineering schools, arts and sciences and computer science programs, and schools of applied technology. Degrees granted include: EMBA, MBA with various concentrations in E-business, Masters of Management with various E-business concentrations, MS with various E-business concentrations, MS in E-business, MS in Information Technology with concentrations in E-business, MS in Marketing with concentration in E-commerce, MS in Computer Science with concentration in Electronic Commerce, and many others.

With this wide variation in both school focus and degree offered, a key question that must be considered is, how much do these factors impact the curriculum that is presented to students? Etheridge et al (2001) reported on E-business programs in Association to Advance Collegiate Schools of Business International (AACSB) accredited schools which are a small subset of all schools offering these programs, and provided no comparison to other schools or models. While many studies restrict themselves only to AACSB schools, this paper takes a broader approach and looks at other schools as well in order to provide a more complete answer to the question. The study reviews E-business and E-commerce programs in schools across North America, Europe, and Hong Kong. It includes AACSB accredited schools, schools certified by the Certified E-Commerce Consultants (CEC), and the top 25 techno-MBA programs as determined by E-business practitioners in Computerworld magazine. 
This paper is a preliminary study to determine if the problems mentioned above are widespread and if they significantly impact program offerings provided by the different groups of skills. Questions considered include:

1. Is there a difference in degree offerings between the different groups of schools?

2. Is there a difference in concentration requirements between MBA and MS E-business concentrations and between different types of schools?

3. Is there a difference in the program offerings between the different degrees or the different groups of schools?

4. Is there a difference in degree focus between the different degrees or the different groups of schools?

\section{Methodology}

This preliminary study studied a large sample of schools with programs in E-business. An initial review of program offerings revealed a wide variety of concentration and degree names housed under the heading of E-business. There were concentrations in MBAs, EMBAs, Techno-MBAs, MS degrees and a variety of other Masters degrees with concentrations E-business, and additionally there were other Masters of Electronic Business or Commerce. There were also certificate and undergraduate programs. Any search on the web would be likely to miss some programs. A decision was made to use lists developed by other organizations to get a good cross section of schools and programs. Three lists of schools with E-business concentrations in MBAs, Technical MBAs, or MS programs were reviewed.

\section{School Selection}

First, the AACSB web site (www.aacsb.edu/e-commerce) was reviewed. This site identified 84 different E-business programs at AACSB accredited schools. A review of the program web sites provided enough curriculum information to be included in the study for only 77 of the programs. Results obtained are quite similar to Etheridge et al (2001) which identified the same number. The programs fell generally into four categories, Master of Science in E-business or similar area, MBA with a concentration in E-business or similar area, BS or BA, and finally non-degree certificate programs. When the certificate programs and undergraduate programs were eliminated only 53 programs remained for the study.

Next, a search was made of the Certified E-Commerce Consultants web site (www.icecc.com), and Ebusiness programs that they identified as effectively preparing students for certification as E-commerce consultants were reviewed. These programs were more varied than those found at the AACSB site and contained several programs from Europe, Canada, and Hong Kong. Here too, programs were of four types, MBA, MS (with a wide variety of concentrations), BS, or certificate. The total number of programs identified here was 96. When the Certificate and BS programs were eliminated, the number of programs remaining was 79 . Of these 67 had sufficient on-line curricular information to be included in the study.

Third, the 25 top technology MBA programs in the country as selected by Computerworld magazine (1999) were reviewed to determine if they had E-business/commerce programs. Only 18 had a clearly defined E-business concentration or focus. Of these only 14 had sufficient curricular information on-line to be included in the study.

This methodology produced a pool of 134 programs. Several schools (12) appeared on all three lists. Because of their impact on the Top 25 schools list, they were used in the analysis for those programs, but were removed from the other lists. It also is an indication at how AACSB schools typically are the highest ranked programs. This reduced the number of programs considered to 110. There were a significant number of duplications in the CEC and AACSB lists as some schools appeared on both lists. Since elimi- 
nation of these schools from the lists would significantly affect the analysis of the school groups, these schools' programs remained in the analysis of each group. As a result the number of unique programs reviewed is only 79 .

\section{Program Offerings}

With this list of programs, the next step in answering the research questions was to determine what the various programs are currently offering. Each program was reviewed and all required and elective courses were listed. As each school's curriculum was reviewed the courses were combined into the composite list of courses for the group of schools being reviewed. When all of the schools in a group had been reviewed, combining courses with similar titles or descriptions reduced the number of courses on the composite list. For example, the course E-commerce Introduction and Basics of E-business were counted as one course. There was such breadth and variety that more than 100 unique courses remained.

Next, the four most widely used courses for the AACSB group were tabulated. In the MBA programs, the top four courses were selected as that was the average number of courses required in the MBA concentration. The process was repeated for CEC and Top 25 groups of MBA programs. The same process was then used for the MS programs for each group. The only difference was that the top six courses used were tabulated since that was the average number of courses required for E-business concentrations in the MS programs.

The third step was to use the information obtained to determine if there were observable differences between the groups of schools, for either the MBA or MS degrees. With this information it was then possible to answer the questions being considered and discuss the possible impact these differences have for the programs, potential students, and organizations that hire these students.

\section{Findings}

Data was collected and reviewed for each of the questions mentioned above. The following describes the research findings for each of the questions that were postulated.

\section{Is there a difference in degree offerings between the different groups of schools?}

The breakout of MBA degrees to MS degrees varies significantly by group and is shown in Table 1. Looking at each group some points can be made. The AACSB schools were the most balanced as a group with 30 out of the $53(56 \%)$ of the programs reviewed being MBA programs and $23(44 \%)$ being MS programs of some type. The CEC schools were heavily weighted toward Masters programs with 46 out of the 67 (69\%) programs reviewed being MS programs and only 21 (31\%) being MBA programs. The Top

Techno-MBA schools were heavily slanted to the MBA with 9 out of 14 (64\%) being MBA programs and only $5(36 \%)$ being MS programs.

In this study overall there are more E-business MS degree programs than MBA programs, 74 to 60, but it

\begin{tabular}{|l|l|l|l|l|}
\hline & MBA & MS \\
\hline & Percent & Number & Percent & Number \\
\hline AACSB & $56 \%$ & 30 & $44 \%$ & 23 \\
\hline CEC & $31 \%$ & 21 & $69 \%$ & 46 \\
\hline Top 25 & $64 \%$ & 9 & $36 \%$ & 5 \\
\hline
\end{tabular}

Table 1. Degree Programs Offered by Schools in the Study 
is more important to look at the groups. Business schools as exemplified by the AACSB and Top 25 Techno MBAs concentrate more on the MBA. Where there is a mixture of business and other schools such as found in the CEC list, then the MS degree is the most prevalent.

\section{Is there a difference in concentration requirements between MBA and MS programs and/or between different types of schools?}

A review of the MBA degree requirements showed no significant difference in the number of courses required for a concentration between the groups of schools. For the MBA the number of required courses varied between 3 and 5 at all schools with the average being 3.7 for AACSB schools, 3.75 for CEC schools and 3.7 for the Top 25 schools.

A review of the courses offered and prerequisite requirements showed that there was almost no difference at all between the MBA programs whether they were from the AACSB group, the CEC group, or the Top 25 group. Also whether the program was called a Techno-MBA or MBA with an E-business concentration or an EMBA, they did not differ significantly in either the number of E-business courses required or the prerequisites required, although the type of courses presented had some variation.

The MS programs had more variation both in courses offered and prerequisite requirements. The range in number for courses required in an MS E-business concentration varied from three to seven courses. Here as with the MBA the average was fairly consistent with AACSB schools averaging 5.6 courses, CEC schools averaging 5.7 courses, and the Top 25 schools averaging 5.6 courses. As a whole there was little difference between the groups. Differences between programs were, however, apparent when looking at individual programs within the groups. This seemed to be directly tied to the school in which the degree was offered and the actual degree name, which often indicated a unique focus. For example the MS in Computer Science with a concentration in E-business had a more rigid list of prerequisites and technical courses than that found at business schools. An MS in Marketing with an E-business concentration had a large number Marketing related courses that were not found in other programs.

In general it appears that the number of courses required for a concentration in an MBA and an MS seems fairly well defined and implemented regardless of school, and any major differences are tied to individual school differences rather than group issues.

\section{Is there a difference in the program offerings between different types of school?}

This is best answered in two parts. The number of unique courses offered by the various programs is considered first. The most commonly offered courses are then considered.

\section{Number of Unique Courses}

The number and breadth of courses offered was extensive in both the MBA and MS programs. Even when courses with similar names and subject were combined the breadth and number of courses offered was quite large. The survey tabulated more than 100 unique courses for the various programs for the groups

\begin{tabular}{|l|l|l|}
\hline & MBA & MS \\
\hline AACSB & 27 & 46 \\
\hline CEC & 58 & 54 \\
\hline Top 25 & 21 & 25 \\
\hline
\end{tabular}

Table 2. Number of Unique Course Offerings of schools and the results are compiled in Table 2. The table shows that the CEC schools had the greatest number of unique courses for both the MBA and the MS programs. This variation is partly a function of the number of programs reviewed because almost every program had at least one or two unique courses included in their pro- 


\begin{tabular}{|l|l|l|l|}
\hline Courses/Topics & AACSB & CEC & Top 25 \\
\hline Intro to E-business & $51 \%$ & & $56 \%$ \\
\hline E-business Technology & $72 \%$ & & \\
\hline E-business marketing & $82 \%$ & $74 \%$ & $79 \%$ \\
\hline Data mining/data bases & $39 \%$ & & \\
\hline Legal Issues and Ethics & & $62 \%$ & \\
\hline E-business Strategy & & $81 \%$ & $65 \%$ \\
\hline Supply Chain Management & & $47 \%$ & $42 \%$ \\
\hline
\end{tabular}

Table 3. Most Often Offered MBA Courses

gram offerings. The least breadth and number of course offerings was found among the Top 25 schools, but this is most certainly because of the small number of programs considered in this group. The AACSB schools, even though the number of programs reviewed was fairly large, had comparatively low numbers of course offerings for the MBA, but had a relatively large number of courses for the MS programs. The low number of courses for the MBA E-business concentration in the AACSB schools is probably partly a function of the requirements needed to meet accreditation standards. The MS programs with their higher number of required courses, broader base of students, and wide range of schools consistently generated a wider range of courses. The large difference in course offerings between the AACSB school MBA programs and CEC school MBA programs seems to indicate that the expectations for CEC requirements for E-business are not as specific and allow more flexibility that the more general AACSB accreditation process.

The breadth of course offerings indicated in Table 2 reveals the potential for considerable variation in what students are presented in the same concentration at different schools. Offerings are only part of the subject. Another critical point is which courses are offered most often.

\section{Commonly Offered Courses}

Table 3 identifies the four most commonly offered courses in MBA programs. It shows that for AACSB MBA programs only two of the listed courses appear in more than $50 \%$ of the programs. Table 3 shows similar course offerings for the CEC and top 25 schools in three of four most commonly offered courses. It is important to point out that no course was offered in $100 \%$ of the schools reviewed. The highest was $82 \%$ and the lowest was $37 \%$. Given the breadth and number of offerings available as noted above, this indicates that there is significant variation in what is being offered in programs at these individual schools as well. This means that many programs could have an entirely different set of courses than the ones shown here. The fact that no specific course was required in all programs also means that the focus of the concentration can change significantly depending on the individual school and program. For example, within the survey group there were two programs at schools where students could take as many as three marketing courses in their MBA E-business concentration. Another school focused on courses in knowledge management, operations management, and decision being key parts of their E-business program offerings. There are, also, significant differences in courses are offered to students in MBA programs between the groups.

There is more similarity between the CEC and top 25 than there is between the AACSB and the others. The difference could be in the audience that they are trying to reach. The flagship program at AACSB schools is the MBA. As such, the general business manager and those aspiring to upper level management are the key audience. It could be expected that concentration courses would focus on the higher level is- 


\begin{tabular}{|l|l|l|l|}
\hline COURSE/Topic & AACSB & CEC & Top 25 \\
\hline E-business marketing & $84 \%$ & $71 \%$ & $74 \%$ \\
\hline E-business technology & $75 \%$ & $77 \%$ & $61 \%$ \\
\hline E-business programming & $53 \%$ & & \\
\hline Security & $53 \%$ & & \\
\hline Capstone/ project/ practicum & $47 \%$ & & $56 \%$ \\
\hline Law and Regulations & $32 \%$ & $46 \%$ & $43 \%$ \\
\hline Fundamentals of E-business & & $36 \%$ & \\
\hline Strategy & & $32 \%$ & \\
\hline E-business Management & & $24 \%$ & $38 \%$ \\
\hline Systems Analysis and Design & & & $29 \%$ \\
\hline DBMS/Data mining & & & \\
\hline
\end{tabular}

Table 4. Most Offered MS Courses

sues, but the AACSB schools in this sample tended to have more technically focused courses than the other groups.

The MS groupings also show variation between the groups, and Table 4 below summarizes those points. Again no single course is found in all the schools, although the most commonly used course is used slightly more often than it was for MBA programs. In this case the remaining courses tended to have lower use rates than the MBA programs. This is due to several reasons, first there were more programs reviewed so there were more courses that could be included. Also these programs had a broad range of schools offering them. Thus a computer science E-business concentration had proportionally more technical and less business courses than that program offered in business schools. Similarly a Masters in Ecommerce Management had proportionally more business courses. This increased the number of courses offered and lowered use of the highest used courses. It was obvious that program parentage had significant influence as most outlyers were from Engineering, Computer Science, Applied Technology, Marketing or Accounting programs, rather than general business programs.

As noted with the MBA, the few standard courses mean a wide variation in what a particular student receives at a particular institution. There was more general consistency in these courses than those found in the MBA. Looking at Table 4, 50\% of the six highest use courses are the same in all three groups of schools. Once again, however, the CEC and Top 25 schools exhibit a closer match in course use than the AACSB schools.

\section{Is there a difference in focus of these programs?}

From the sample here, the AACSB MS programs as a rule tended to be more technically focused than the other MS programs. This could partially be explained because many have an MBA program offered as well. The MBA could then focus more on the managerial issues and leave the more technical focus for the MS degree. The Top 25 schools had a slightly less technical focus. This was true in spite of the fact that their purpose is to educate technically based managers. This might be because as techno-MBAs several had some technology courses worked into the curriculum in addition to what was covered in the concentration. The CEC schools are preparing those to function in the CEC environment and their focus is 
broader than the other two. Many of the CEC schools had only the one degree and therefore often had to offer a more balanced degree with a split between technical and business topics. Also they had the purpose of preparing future consultants so a broader approach might be more appropriate.

\section{Discussion}

The results give an interesting picture, but what does all mean? Since this study is only looking at aggregate data, not much can be said about specific programs or about the students that they are producing. Some general observations can be made. From the course descriptions of the courses offered, it appears that most MBAs are more focused on managerial issues and concerns. The MS programs seem clearly split. When specific MS programs are reviewed, some were hardly distinguishable from the MBA. Others seemed much closer to a computer science degree both in approach and topics covered. In some there was almost no effort to consider the managerial or business concerns associated with E-business. The management, marketing, and accounting based E-business programs, as might be expected had the most diversity and were really unique unto themselves even though they did offer some of the courses found in other MS programs.

\section{Program Variation}

The most obvious question is why is there such variation and so little consistency across programs? One answer might be to consider how many of these programs were developed. A fast development technique such as fast-cycle curriculum development (Fedorowicz \& Gogan, 2001) has some inherent limitations can lead schools to develop programs that mirror their faculty's skills and needs of local employers rather than creating a balanced educational experience. This is exacerbated by the fact that most schools have only a small number of faculty who have education, or expertise in E-business. Most come from other disciplines thus it is likely that their programs would mirror their previous or main discipline. Schneberger et al (2000) discusses how this interdisciplinary approach, if done correctly, can bring strength to these programs. This requires much effort and is difficult to achieve. The practitioner and academic meetings to develop E-business programs such as that described by Mitchell and Straus (2001) highlights both the advantages and disadvantages inherent in the process. They can identify the major technical areas needed for E-business programs, but often miss the issues to be addressed at the master's level of integration into the business, strategic planning, legal issues, management concerns, financial implications, supply chain management, and other organizational issues which are key to the education of masters level business students.

\section{Program Goals}

Looking at the MBA programs, the mean number of concentration courses for all MBA programs in the study was 3.7. Such a small number of courses means that the MBA student graduates with some knowledge of E-business, but it is a rather limited knowledge set. In general students may have enough knowledge to oversee an E-business operation, but wouldn't have the detailed knowledge and technical understanding to actually develop the technical elements of an E-business program in an organization. Given the traditional role of the MBA to prepare managers to mange all aspects of a business this makes sense, but it does not prepare them to be E-business experts.

Looking at the MS programs, the mean number of concentration courses for all MS programs in the study was 5.7. This number provides the potential for students to have a reasonable understanding the issues and skills required to be effective in E-business. The problem is that with the wide variation of course offerings available to students, there is no consistent core presented, and graduates from these programs have a widely varying skills. 
In spite of research which shows that there are several audiences that should be addressed in E-business programs (King et al, 2001), not all audiences' needs are being fully addressed by current E-business programs. The first audience is the general manager or functional manager in a business. Many programs ignore issues and concerns for this audience and assume that managers already have this key information. There is also an audience that has to understand the technology and how to truly integrate e-business in the organization. Finally, there is a technical audience that must know how to build the E-business system. Most of the programs reviewed failed to even indicate the audience that their program was designed for; a few clearly articulated explained the focus of their program and what they were preparing students to do. Given the variety of programs and wealth of potential offerings this should be done on a more regular basis.

\section{Conclusion}

Even though the data observed are based on a convenience sample the comparatively large sample size provides sufficient data for analysis. There are several areas which could be the subject of further research. This study reveals a large variation between schools, but the difference seems to be driven more by the interests and background of the faculty than the type of degree offered. E-business programs have been developed in several disciplines. Material presented in E-business concentrations often seems more linked to the base discipline than to the issues and concerns of E-business. This problem appears to be wide spread. What is its impact, and how can it be addressed? There is wide variation in what different schools present as E-business programs. This means that it requires more research than normal on the part of prospective students and prospective employers of these students to determine just what these programs cover. Schools planning to initiate an E-business concentration need to look at research on the subject to identify topics which all students must be presented. Then they can look at the student audience and using their faculty strengths create their dialect of the E-business program, but it should be a dialect, not a new language.

The field is still developing and the changes in technical capabilities impact what E-business can do for organizations. There is still no general consensus on what should be the core knowledge in the concentration, although the top courses listed in Tables 3 and 4 appear to be a start in this direction. Will the programs eventually develop a standard core? They probably will in the future, but faculty are the ones that will have to make it happen. We must design programs that are truly responsive to the needs of student, but which are also academically sound and which provide the knowledge that our graduates will need in the future as well as now.

\section{References}

Barlas, D. (2001). E-Business on Campus: Programs at Leading B-schools suggest the field is coming of age. Line 56, 6, 2021.

Booker, E. (1998). E-Commerce Stays on Course. Internetweek, 738, October 26, p25.

(1999). Top 25 Techno MBAs. Computerworld, 22, 39, 27-31, September 27, 1999.

Deakin, M. (2001). E-biz: Big Major on Campus. Computerworld, 35. 27, 55-56.

Etheridge, H., Hsu, K., \& Wilson, T. (2001). E-Business Education at AACSB-Affiliated Business Schools: A Survey of Programs and Curricula. Journal of Education for Business, 76, 6, 328-331.

Fedorowicz, J. \& Gogan, J. (2001). Fast-cycle Curriculum Development Strategies for E-business Programs: The Bentley College Experience. Journal of Education for Business, 76, 6, 318-327.

Hermann, G. \& Pernul, G. (1999). Viewing Business-Process Security from Different Perspectives. International Journal of Electronic Commerce, 3, 3, 89-103.

King, C., Frank, S., Platt, R. (2001). E-commerce Courses: Overview of Nature and Content. Journal of Education for Business, 76, 6, 332-337. 
Lederer, A., Mirchandani, D., \& Sims, K. (2001). The search for strategic advantage from the World Wide Web. International Journal of Electronic Commerce, 5. 4, 117-133.

McLoughlin, G. (2000). Electronic commerce. The Journal of Academic Librarianship, 26. 3,196-198.

Mitchell, T. \& Strauss, J. (2001). Practitioner and academic recommendations for Internet marketing and E-commerce curricula. Journal of Marketing Education, 23. 2, 91-103.

Payne, R. (2001). Taking the e-business journey. Industrial Distribution, 90. 8,4.

Schneberger, S., Parent, M., and Haggarty, N. (2000). Teaching E-commerce: A Multidisciplinary Approach. Journal of Informatics Education and Research, 2, 2, 1-8.

Sendall, P. (1999). A Survey of Electronic Commerce Courses. Proceedings of the $14^{\text {th }}$ Annual Conference of the International Academy for Information Management, Charlotte, NC, 9-13.

Teo, T. \& Too, B. (2000). Information systems orientation and business use of the Internet: An empirical study. International Journal of Electronic Commerce,4. 4, 105-130.

Williams, H., Kwak, Y., Morrison, J., \& Oladunjoye, G. (2000). Teaching the effects of electronic commerce on business practices and global stability. Journal of Education for Business, 75. 3, 178-182.

\section{Biography}

James Novitzki is an Associate Professor and Chairman of the Information Technology Department in the School of Professional Studies in Business and Education at Johns Hopkins University. He teaches an introduction to E-business and E-business Strategy courses several times a year. Dr Novitzki is the author of more than 20 papers and articles on the subject of improving the quality of information technology education. 